\title{
Acquired Resistance to Mefenoxam in Sensitive Isolates of Phytophthora infestans
}

\author{
Richard Childers, Giovanna Danies, Kevin Myers, Zhangjun Fei, Ian M. Small, and William E. Fry
}

First, second, third, fifth, and sixth authors: Department of Plant Pathology, Cornell University, Ithaca, NY 14853; and fourth author: Boyce Thompson Institute and USDA-ARS, Cornell University, Ithaca, NY 14853.

Accepted for publication 9 September 2014.

\begin{abstract}
Childers, R., Danies, G., Myers, K., Fei, Z., Small, I. M., and Fry, W. E. 2015. Acquired resistance to mefenoxam in sensitive isolates of Phytophthora infestans. Phytopathology 105:342-349.

The systemic fungicide mefenoxam has been important in the control of late blight disease caused by Phytophthora infestans. This phenylamide fungicide has a negative effect on the synthesis of ribosomal RNA; however, the genetic basis for inherited field resistance is still not completely clear. We recently observed that a sensitive isolate became tolerant after a single passage on mefenoxam-containing medium. Further analyses revealed that all sensitive isolates tested (in three diverse genotypes) acquired this resistance equally quickly. In contrast, isolates that were "resistant" to mefenoxam in the initial assessment (stably

resistant) did not increase in resistance upon further exposure. However, there appeared to be a cost associated with acquired resistance in the initially sensitive isolates, in that isolates with acquired resistance grew more slowly on mefenoxam-free medium than did the same isolates that had never been exposed to mefenoxam. The acquired resistance of the sensitive isolates declined slightly with subsequent culturing on medium free of mefenoxam. To investigate the mechanism of acquired resistance, we employed strand-specific RNA sequencing. Many differentially expressed genes were genotype specific, but one set of genes was differentially expressed in all genotypes. Among these were several genes (a phospholipase "Pi-PLD-like-3," two ATP-binding cassette superfamily $[\mathrm{ABC}]$ transporters, and a mannitol dehydrogenase) that were upregulated and whose function might contribute to a resistance phenotype.
\end{abstract}

Phytophthora infestans is the causal agent of late blight of potatoes and tomatoes and a member of the Oomycota. The late blight disease is one of the most devastating of plant diseases, and growers are very concerned about it. Effective management of the disease includes sanitation, host resistance (if available), and appropriate use of fungicides. The high efficacy, systemicity, and oomycete specificity of phenylamide fungicides like mefenoxam resulted in their widespread usage soon after their commercial release during the late 1970s (5). The phenylamides inhibit ribosomal RNA (rRNA) biosynthesis (polymerase complex I) in the target pathogens.

Unfortunately, resistance to mefenoxam appeared during the early 1980s $(7,8)$. Such resistance is inherited by progeny, and apparently controlled by one or a few dominant genes $(14,17)$. Recently a mutation in a subunit of RNA polymerase 1 was demonstrated to be responsible for resistance in a majority of insensitive isolates (22). The emergence of resistance was followed by a decrease in the usage of mefenoxam to control late blight (9). Interestingly, following the decline in use of mefenoxam, sensitive populations of $P$. infestans have again been detected (12). In very simple clonal populations consisting of a few clonal lineages that have been characterized phenotypically, it is possible to predict mefenoxam sensitivity based on genotypic analysis (6). Because genotypic analyses are typically much quicker than phenotypic analyses, genotypic data can be used to inform growers of the likely fungicide sensitivity of the lineages in their region $(6,10)$.

Corresponding author: W. E. Fry; E-mail address: wef1 @ cornell.edu

The first and second authors contributed equally to this work.

* The $e$-Xtra logo stands for "electronic extra" and indicates that the online version contains one supplementary figure.

http://dx.doi.org/10.1094/PHYTO-05-14-0148-R

(C) 2015 The American Phytopathological Society
The sensitivity or resistance of $P$. infestans to mefenoxam is commonly assessed in vitro by measuring the radial growth of the pathogen in response to diverse concentrations of the fungicide in amended media $(11,18)$. Previously, sensitivity has been defined as at least a $60 \%$ reduction in radial growth of colonies grown in agar amended with $5 \mu \mathrm{g} \mathrm{ml}^{-1}$ mefenoxam compared with colonies grown in mefenoxam-free medium $(6,11,18)$. The recent predominance in the United States of clonal lineages (US-22, US-23, and US-24) that are sensitive to mefenoxam in such assays means that mefenoxam can once again be used to suppress late blight in the United States (10).

During the course of our in vitro assays to determine mefenoxam sensitivity of diverse isolates, we observed that one isolate appeared to become resistant after a single passage through mefenoxam-containing medium. Previous reports indicated that "in vitro" resistance appeared after repeated exposures to sublethal doses of mefenoxam $(3,26)$, but the speed of adaptation, the generality, and potential mechanisms have not been reported. For the purposes of this study, we have defined resistance as the ability of the isolate to grow at a rate greater than $40 \%$ of the control at both 5 and $100 \mu \mathrm{g} \mathrm{ml}^{-1}$ mefenoxam. Given the speed of this acquisition, a genetic basis for this change in resistance seemed improbable, and therefore it seemed more likely that some physiological process had mediated this change. We hypothesized that "acquired resistance" to mefenoxam is a general characteristic of $P$. infestans, that it develops very rapidly upon exposure, and that gene expression studies might reveal candidates to explain this phenomenon. Thus, the goals of our study were to confirm the acquired resistance to mefenoxam and to characterize that resistance in diverse genotypes of $P$. infestans. Upon confirmation of the phenomenon, we employed wholetranscriptome sequencing to investigate gene expression differences between initially sensitive isolates and their derivatives with acquired mefenoxam resistance. 


\section{MATERIALS AND METHODS}

Clonal lineages used. The isolates used in this study belonged to four clonal lineages. Different sets of genetic markers (described in Fry et al. [10]) were used to determine the isolate's genotype. The genetic markers used were 12 microsatellite loci, a restriction fragment length polymorphism assay using the moderately repetitive DNA probe RG57, and an allozyme test using the glucose-6-phosphate isomerase. Furthermore, the mating type of each isolate was determined. With the exception of some minor variations within the microsatellite profiles, these individuals were identical within their assigned clonal lineage for all markers analyzed. Mutations are expected within clonal lineages, especially in rapidly evolving markers such as simple sequence repeats.

We used one isolate of US-8, two of US-22, two of US-23, and three of clonal lineage US-24. In previous assays, isolates of the US-8 clonal lineage had been identified as resistant $(6,11)$. In contrast, isolates belonging to clonal lineages US-22, US-23, and US-24 had been identified as sensitive $(6,13)$. For the purposes of this study, we define a sensitive strain as one that grows at less than $40 \%$ of the control at both 5 and $100 \mu \mathrm{g} \mathrm{ml}^{-1}$ mefenoxam. Given that isolates of clonal lineage US- 8 had previously been found to be consistently and stably resistant to mefenoxam in vitro, this US-8 isolate was used as a positive control for mefenoxam resistance. All isolates were cultured on pea agar (6) and maintained at 20 to $22^{\circ} \mathrm{C}$. Isolates belonging to clonal lineages US-22 and US-23 are pathogenic to both potato and tomato (6), whereas isolates belonging to clonal lineages US-8 and US-24 are pathogens primarily of potato.

Mefenoxam sensitivity assays. Mefenoxam sensitivity was assayed as radial growth on mefenoxam-amended medium, conducted as described previously by Therrien et al. (27) with the exception that mefenoxam was substituted for metalaxyl. Isolates were grown on pea agar amended with Ridomil Gold SL (Syngenta, Greensboro, NC), which contains $49 \%$ mefenoxam as the active ingredient; the final concentrations of the active ingredient were 0,5 , or $100 \mu \mathrm{g} \mathrm{ml}^{-1}$. Although the use of a dose range to calculate $\mathrm{EC}_{50}$ values could potentially give more insights into the dose-response relationship, the technique of using discriminatory dosages $\left(0,5\right.$, or $100 \mu \mathrm{g} \mathrm{ml} \mathrm{m}^{-1}$ of mefenoxam) has been widely used for over 20 years and adequately serves the current purpose. Due to inherent variation in the rate of growth among isolates, a standard colony diameter on the control plates $\left(0 \mu \mathrm{g} \mathrm{ml}^{-1}\right.$ mefenoxam), rather than a standard incubation time was used to determine the period of incubation for each isolate. Therefore, for each sensitivity assay, colony diameter on each treatment was measured when the growth of the isolate on the control plates $\left(0 \mu \mathrm{g} \mathrm{ml}^{-1}\right)$ reached 60 to $70 \mathrm{~mm}$. Subculturing from all isolates was carried out when growth on medium containing mefenoxam was at least $20 \mathrm{~mm}$ in diameter. All subculturing for each isolate was done on the same day. Growth on mefenoxam-amended plates at 5 and $100 \mu \mathrm{g} \mathrm{ml}^{-1}$ was presented as a percentage of the growth on the mefenoxam-free control plates.

Initial sensitivity and acquisition of resistance assays. For each isolate, initial sensitivity and occurrence of "acquired resistance" were assessed by determining the sensitivity of an isolate before and after it had been exposed to mefenoxam. To test for initial sensitivity, a subculture from each isolate (with no previous exposure to mefenoxam) was transferred to media containing 0,5 , and $100 \mu \mathrm{g} \mathrm{ml}^{-1}$ mefenoxam (Fig. 1A). To test for acquired resistance, a subculture from each isolate with prior exposure to mefenoxam (5 or $100 \mu \mathrm{g} \mathrm{ml} \mathrm{m}^{-1}$ ) was assessed for mefenoxam resistance by transferring mycelia to medium containing 0,5 , and $100 \mu \mathrm{g} \mathrm{ml}^{-1}$ mefenoxam and then comparing growth on mefenoxam-containing medium with that on mefenoxamfree medium (Fig. 1A). To ensure that acquired resistance was not a result of spontaneous mutations, we conducted the experiment at least three times. In addition, subcultures that had never been exposed to mefenoxam were evaluated on media containing 0,5 , and $100 \mu \mathrm{g} \mathrm{ml}^{-1}$ mefenoxam at each transfer stage during the experiment.

Effects of previous mefenoxam exposure $\left(0,5\right.$, and $\left.100 \mu \mathrm{g} \mathrm{ml}^{-1}\right)$, subsequent mefenoxam exposure $\left(5\right.$ and $\left.100 \mu \mathrm{g} \mathrm{ml}^{-1}\right)$, lineage, and their full factorial interactions on colony growth were analyzed using JMP 10.0.0 (SAS Institute, Cary, NC). Standard least-square analysis was used; replications were considered random terms, while mefenoxam exposures, lineage, and interactions were considered fixed effects. To determine whether means of percent colony growth on mefenoxam-amended plates for each lineage differed between previous exposure concentrations, a Tukey's honest significant difference (HSD) test with $\alpha=0.05$ was performed.

Maintenance of acquired resistance assays. After an isolate had acquired resistance, the maintenance of that resistance was evaluated after repeated subculturing in the absence of mefenoxam (Fig. 1B). Each isolate was assayed for mefenoxam sensitivity (described above) after one, two, and three subcultures on mefenoxam-free medium.

After identifying the group of lineages that had demonstrated acquired resistance (US-22, US-23, and US-24), effects of previous mefenoxam exposure $\left(0,5\right.$, or $\left.100 \mu \mathrm{g} \mathrm{ml}^{-1}\right)$, number of transfers through mefenoxam-free medium (one, two, or three), subsequent mefenoxam exposure (5 or $100 \mu \mathrm{g} \mathrm{ml}^{-1}$ ), and their full factorial interactions on colony growth were analyzed using JMP 10.0.0. Standard least-square analysis was used, where isolates and replications were considered random terms, while previous mefenoxam exposure, number of mefenoxam-free transfers, subsequent mefenoxam exposure, and interactions were considered fixed effects. To determine whether relative growth on mefenoxam-amended plates changed after transfers through mefenoxam-free medium, a Tukey's HSD test with $\alpha=0.05$ was performed.

Slower growth due to acquired resistance. After an isolate had acquired resistance, the growth rate of the isolate was evaluated by measuring colony growth in the absence of mefenoxam after one, two, three, and four consecutive subcultures on mefenoxam-free media (Fig. 1C). Effects of previous mefenoxam exposure $\left(0,5\right.$, or $\left.100 \mu \mathrm{g} \mathrm{ml} \mathrm{m}^{-1}\right)$, number of mefenoxam-free transfers (one, two, three, or four) and their interaction on colony growth were analyzed using JMP 10.0.0. Standard least-square analysis was used, where isolates and replications were considered random terms, while previous mefenoxam exposure, number of transfers through mefenoxam-free medium, and their interaction were considered fixed effects. To determine whether means of percent colony growth on mefenoxam-free media differed for each previous exposure concentration, a Tukey's HSD test with $\alpha=0.05$ was performed.

Whole-transcriptome sequencing. Strand-specific RNA sequencing, following the method of Zhong et al. (34) was used to examine gene expression differences between nonexposed isolates and subcultures of the same isolates after acquisition of resistance to mefenoxam. Isolates analyzed were one individual of US-8 as a stably resistant control, one individual of US-23, and two individuals of US-24. Two treatments were used for each isolate; in the first, the isolate was cultured on pea agar without mefenoxam, and in the second, the isolate was cultured on pea agar containing $100 \mu \mathrm{g} \mathrm{ml}^{-1}$ mefenoxam. These treatments were continued for three successive subcultures. Subsequently, those individuals that had been grown on mefenoxam-free medium were transferred to pea broth free of mefenoxam, and those individuals grown on pea medium with mefenoxam were transferred to pea broth with mefenoxam $\left(100 \mu \mathrm{g} \mathrm{ml}{ }^{-1}\right)$. For individuals growing in the presence of mefenoxam, the mycelia were harvested after 6 to 12 days. For individuals growing in the absence of mefenoxam, the mycelia were harvested after 4 to 8 days.

The experiment was conducted three times for three biological replications. Each biological replicate was started on a different 


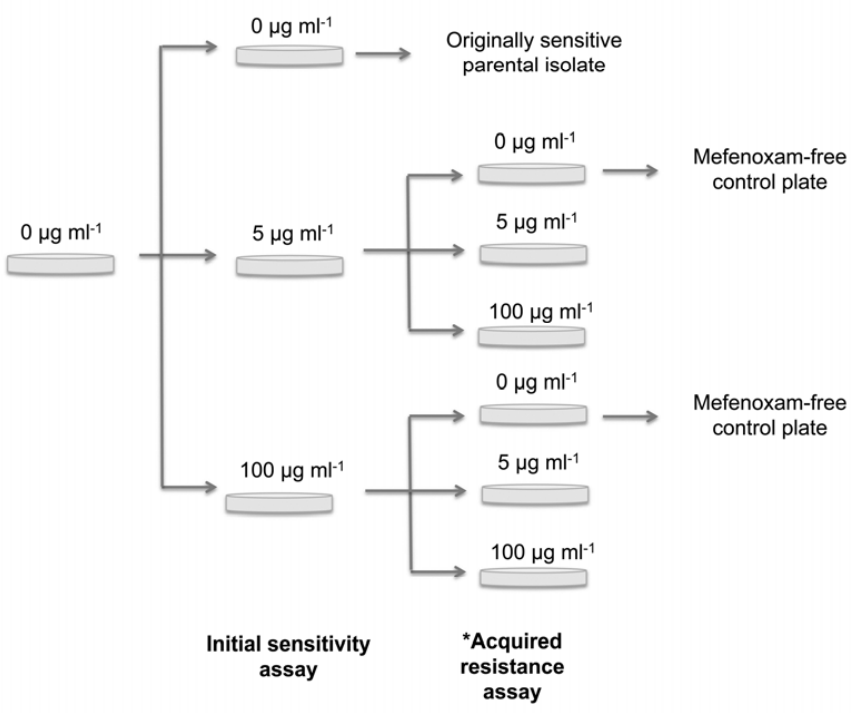

B

Maintenance of acquired resistance
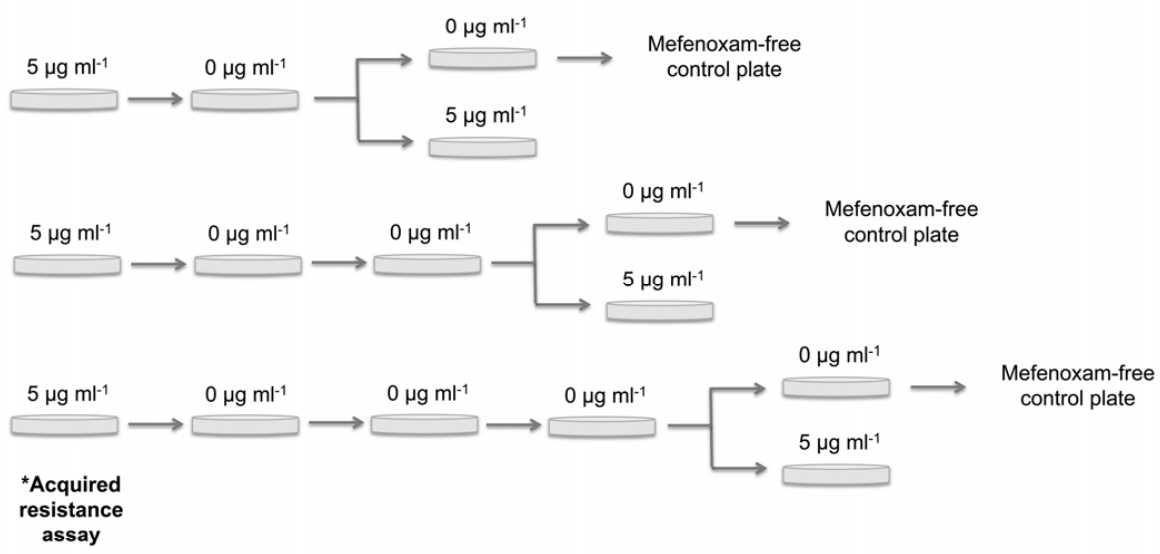

C

Loss of fitness due to acquired resistance
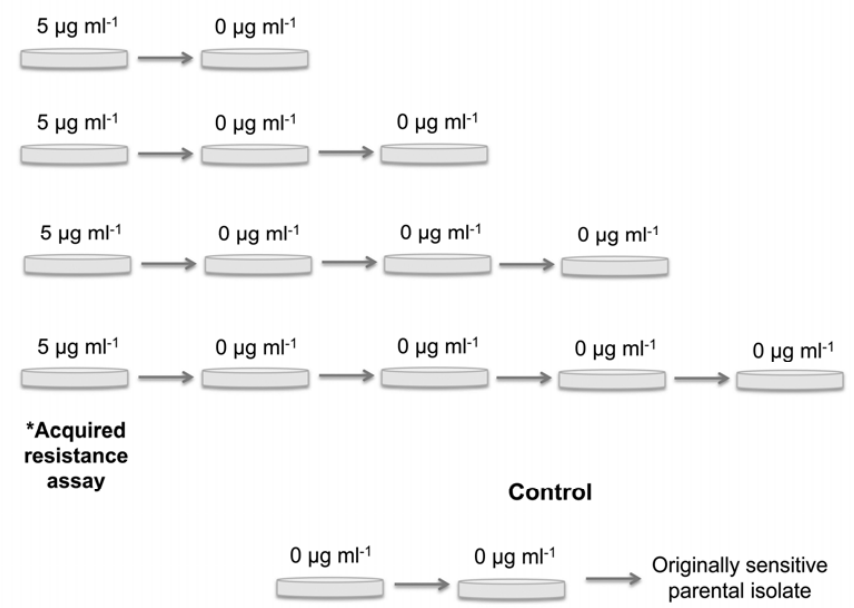

Fig. 1. Experimental design and culturing sequence. A, Acquired resistance was determined by comparing the resistance to mefenoxam of isolates before and immediately after an exposure to mefenoxam. Initial sensitivity to mefenoxam was assessed by transferring isolates that had never been exposed to mefenoxam to 0,5 , and $100 \mu \mathrm{g} \mathrm{ml}^{-1}$ mefenoxam. Isolates that had been exposed to either 5 or $100 \mu \mathrm{g} \mathrm{ml}^{-1}$ mefenoxam were subsequently transferred again to 0,5 , and $100 \mu \mathrm{g} \mathrm{ml}{ }^{-1}$ mefenoxam (*acquired resistance assay). B, Maintenance of acquired resistance was assessed by transferring isolates that had been exposed twice through mefenoxam-amended media through a series of one, two or three transfers on mefenoxam-free media. Maintenance of acquired resistance for each isolate was then assessed on mefenoxam-amended media. The same procedure was followed for isolates initially exposed to $100 \mu \mathrm{g} \mathrm{ml} \mathrm{l}^{-1}$ mefenoxam. $\mathbf{C}$, To test for loss of fitness due to acquired resistance, isolates that had been exposed twice to mefenoxam-amended media were transferred one, two, three, or four times on mefenoxam-free media. Growth on mefenoxam-free media of initially sensitive isolates was used as a control. This figure illustrates the protocol for isolates exposed to $5 \mu \mathrm{g} \mathrm{ml}^{-1}$ mefenoxam, but the same procedure was followed for isolates initially exposed to $100 \mu \mathrm{g} \mathrm{m} l^{-1}$ mefenoxam. 
date. Within each biological replicate there were two technical replicates. Total RNA was extracted using the RNeasy Plus Mini kit (QIAGEN). Twenty-four libraries (one per sample) were prepared following the method described in Zhong et al. (34), and $20 \mathrm{ng}$ of each library was multiplexed and run on an Ilumina HiSeq 2000 via 100-bp single-end read sequencing in a single lane at the Cornell University Sequencing Core Facility.

Bioinformatic and statistical analysis for the RNAsequencing (RNA-seq) study. RNA-seq reads were first aligned to rRNA and transfer RNA sequences using Bowtie (16), allowing for two mismatches to remove any possible contaminations of these sequences. The resulting filtered reads were aligned to the draft genome of $P$. infestans strain T30-4, available from the Broad Institute (Phytophthora infestans Sequencing Project, Broad Institute of Harvard and MIT, http://www.broadinstitute. org) using TopHat (28), allowing one segment mismatch. Following alignments, raw counts for each gene were normalized to reads per kilobase of exon model per million mapped reads. The raw counts were then processed with the edgeR package (23) to examine genes that were differentially expressed.

We next searched for differences in gene expression that were common among isolates. To ensure consistency among replicates in the analysis of differential expression, tagwise dispersion estimates were used in all cases (23). The default prior.df value (which moderates the weight placed on tagwise versus common dispersion estimates) of 10 was used for all analyses. edgeR automatically controls for false positives by controlling the false discovery rate (FDR), following the method of Benjamini et al. (1).

Differential gene expression between an isolate with versus without acquired resistance was detected, and only genes with an FDR lower than 0.05 were retained. Then, differentially expressed genes that were common to the three originally sensitive isolates (one US-23 and two US-24 isolates) were identified (Table 1). We then explored the possibility that the same genes are differentially expressed also in the stably resistant US-8 (Table 1). Summary statistics were produced with JMP 10.0 (JMP, Version 10.0, SAS Institute Inc.).

qRT-PCR to validate the RNA-seq results. To confirm the RNA-seq results, we performed a real-time reverse-transcriptionPCR (qRT-PCR) for five genes that had a significant differential expression in response to mefenoxam in $P$. infestans. Total RNA was reverse-transcribed using the High-Capacity cDNA Reverse Transcription Kit with RNase Inhibitor (Applied Bio-systems, Carlsbad, CA). Total transcript levels were determined by qRTPCR using the SYBR Green PCR Master Mix (Applied Biosystems), following the manufacturer's protocol.

All genes were assayed in triplicate in 96-well plates, and two biological replicates of each treatment were performed. Controls

TABLE 1. Genes that were significantly differentially expressed in response to mefenoxam in four isolates of Phytophthora infestans (one US-8 isolate, one US23 isolate, and two US-24 isolates [US-24A and US-24B] $)^{\mathrm{a}}$

\begin{tabular}{|c|c|c|c|c|c|c|c|c|c|c|}
\hline \multirow[b]{2}{*}{$\mathrm{Gene}^{\mathrm{b}}$} & \multirow[b]{2}{*}{ Annotation $^{\mathrm{c}}$} & \multicolumn{4}{|c|}{$\log _{2} \mathrm{FC}^{\mathrm{d}}$} & \multicolumn{4}{|c|}{$\mathrm{FDR}^{\mathrm{e}}$} & \multirow{2}{*}{$\frac{\log _{2} \mathrm{CPM}^{\mathrm{f}}}{\text { Average }}$} \\
\hline & & US-8 & US-23 & US-24A & US-24B & US-8 & US-23 & US-24A & US-24B & \\
\hline PITG_00923 & Phospholipase D, Pi-PLD-like-3 & 6.92 & 4.91 & 4.57 & 9.78 & 4.41E-08 & $2.66 \mathrm{E}-05$ & 5.77E-04 & $1.14 \mathrm{E}-13$ & 3.52 \\
\hline PITG_09160 & Secreted RxLR effector peptide, putative & 5.63 & 3.34 & 7.97 & 5.2 & $1.03 \mathrm{E}-04$ & $1.83 \mathrm{E}-02$ & 3.74E-04 & $1.28 \mathrm{E}-04$ & 2.72 \\
\hline PITG_16256 & Conserved hypothetical protein & 3.02 & 2.19 & 2.88 & 5.04 & $1.39 \mathrm{E}-03$ & 4.42E-02 & 3.83E-03 & $2.59 \mathrm{E}-09$ & 1.44 \\
\hline PITG_09063 & Conserved hypothetical protein & NS & 3.23 & 2.85 & 3.23 & NS & $3.85 \mathrm{E}-03$ & $1.79 \mathrm{E}-02$ & $3.85 \mathrm{E}-03$ & 1.82 \\
\hline PITG_07501 & Crinkler (CRN) family protein & 2.89 & 1.3 & 3.87 & 3.61 & $2.56 \mathrm{E}-09$ & $1.12 \mathrm{E}-02$ & $1.33 \mathrm{E}-17$ & $3.96 \mathrm{E}-11$ & 2.41 \\
\hline PITG_16991 & Cell 12A endoglucanase & NS & 1.65 & 1.95 & 4.04 & NS & $2.58 \mathrm{E}-02$ & $1.03 \mathrm{E}-02$ & $1.25 \mathrm{E}-10$ & 3.11 \\
\hline PITG_05795 & Conserved hypothetical protein ${ }^{\mathrm{g}}$ & 2.56 & 2.19 & 2.14 & 2.68 & 7.23E-07 & $1.10 \mathrm{E}-04$ & 5.71E-04 & 3.17E-07 & 2.80 \\
\hline PITG_22087 & ATP-binding cassette (ABC) superfamily & 1.53 & 1.94 & 2.16 & 2.61 & 4.46E-02 & $3.84 \mathrm{E}-03$ & $1.78 \mathrm{E}-03$ & $1.45 \mathrm{E}-05$ & 4.99 \\
\hline PITG_16235 & Secreted RxLR effector peptide, putative & 3.12 & 2.65 & 1.88 & 1.83 & $4.55 \mathrm{E}-05$ & 3.48E-04 & $1.55 \mathrm{E}-02$ & $9.94 \mathrm{E}-03$ & 2.84 \\
\hline PITG_16409 & Secreted RxLR effector peptide, putative & 3.59 & 2.51 & 1.65 & 2.11 & $2.73 \mathrm{E}-08$ & $2.65 \mathrm{E}-04$ & $1.77 \mathrm{E}-02$ & $3.80 \mathrm{E}-04$ & 3.27 \\
\hline PITG_08846 & Mannitol dehydrogenase, putative & 3.58 & 2.19 & 2.27 & 1.78 & $1.09 \mathrm{E}-07$ & $2.39 \mathrm{E}-03$ & $2.68 \mathrm{E}-03$ & $1.42 \mathrm{E}-02$ & 6.01 \\
\hline PITG_02748 & Conserved hypothetical proteing & NS & 1.28 & 1.85 & 1.49 & NS & $3.98 \mathrm{E}-02$ & $2.55 \mathrm{E}-03$ & $9.43 \mathrm{E}-03$ & 2.66 \\
\hline PITG_10995 & Conserved hypothetical protein ${ }^{\mathrm{g}}$ & NS & 1.56 & 1.34 & 1.15 & NS & $3.71 \mathrm{E}-03$ & $2.38 \mathrm{E}-02$ & $3.90 \mathrm{E}-02$ & 5.24 \\
\hline PITG_09097 & Conserved hypothetical protein & NS & 1.32 & 1.27 & 1.43 & NS & 7.39E-03 & $1.78 \mathrm{E}-02$ & $1.56 \mathrm{E}-03$ & 2.89 \\
\hline PITG_15998 & Phospholipase A-2-activating protein, putative & NS & -0.92 & -0.82 & -0.89 & NS & $1.22 \mathrm{E}-02$ & $3.92 \mathrm{E}-02$ & $9.60 \mathrm{E}-03$ & 5.32 \\
\hline PITG_16013 & Conserved hypothetical proteing & NS & -1.01 & -1.39 & -1.09 & NS & $3.85 \mathrm{E}-02$ & $3.16 \mathrm{E}-03$ & $1.69 \mathrm{E}-02$ & 3.28 \\
\hline PITG_16794 & Di- $N$-acetylchitobiase, putative & -1.23 & -1.24 & -0.97 & -1.34 & 7.92E-04 & $5.59 \mathrm{E}-04$ & $1.43 \mathrm{E}-02$ & $5.66 \mathrm{E}-05$ & 3.61 \\
\hline PITG_10079 & Conserved hypothetical proteing ${ }^{g}$ & NS & -1.54 & -1.64 & -1.02 & NS & 3.63E-04 & $5.21 \mathrm{E}-04$ & $2.78 \mathrm{E}-02$ & 2.90 \\
\hline PITG_16795 & Conserved hypothetical protein & -2.17 & -1.55 & -1.51 & -1.94 & $6.75 \mathrm{E}-04$ & 2.32E-02 & 4.05E-02 & $1.73 \mathrm{E}-03$ & 4.78 \\
\hline PITG_04948 & Conserved hypothetical protein & -2.09 & -2.41 & -1.61 & -1.81 & $6.80 \mathrm{E}-04$ & $1.85 \mathrm{E}-03$ & 4.11E-02 & $6.13 \mathrm{E}-03$ & 1.66 \\
\hline PITG_07573 & Conserved hypothetical protein ${ }^{\mathrm{g}}$ & NS & -2.06 & -2.69 & -2.61 & NS & $6.95 \mathrm{E}-03$ & $1.01 \mathrm{E}-04$ & $2.83 \mathrm{E}-05$ & 3.59 \\
\hline PITG_09316 & Secreted RxLR effector peptide, putative & NS & -2.07 & -2.44 & -2.86 & NS & 2.19E-02 & $2.35 \mathrm{E}-03$ & $4.20 \mathrm{E}-05$ & 1.96 \\
\hline PITG_08344 & Conserved hypothetical protein & -4.09 & -5.7 & -6.28 & -4.07 & $1.91 \mathrm{E}-03$ & $2.03 \mathrm{E}-02$ & $7.25 \mathrm{E}-03$ & $9.52 \mathrm{E}-03$ & -0.04 \\
\hline
\end{tabular}

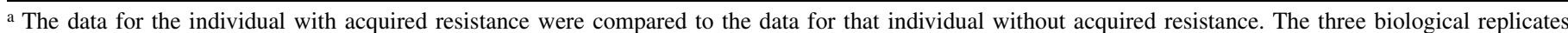
were used to calculate tagwise gene dispersion estimates, favoring genes that behaved consistently across replicates. These estimates were used in a negative binomial model to estimate differential expression from the raw counts for each isolate. Annotations for genes that were shown to be differentially expressed in all individuals with acquired resistance in response to mefenoxam are shown below.

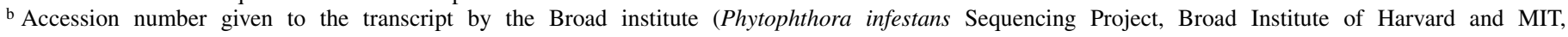
http://www.broadinstitute.org).

c Putative annotated functions of the specified genes.

${ }^{\mathrm{d}} \log _{2}$ of the fold change (FC) in response to mefenoxam exposure.

e False discovery rate.

${ }^{\mathrm{f}}$ Average $\log _{2}$ counts-per-million (CPM). EdgeR provides only a global average of $\log _{2}$ counts-per-million for each gene.

$\mathrm{g}$ Conserved hypothetical proteins for which the closest annotated match has been listed in Table 2 . 
lacking reverse transcriptase and lacking template were included. Results were analyzed with the ABI PRISIM 7700 Sequence Detection System (Applied Biosystems, Foster City, CA) program, and relative expression was calculated using REST 2009 software (21). The genes and primers were as follows: (i) PITG_11969 (ATP-binding cassette superfamily) (FW, GAC GCCCAAGAGTAAAGATG; RV, CCGTTAATGCCCTTGAGT AG); (ii) PITG_00147 (conserved hypotyhetical protein) (FW, CAGGAGCTTCAGCAACAG; RV, GCGAAGATGCGGAAGAC); (iii) PITG_00923 (phospholipase D) (FW, TACCGTTCCCTAC CTCATC; RV, GCCATCCCACTGACATTT); (iv) PITG_05795 (conserved hypothetical protein) (FW, GTTGGAGAAGATGAA AGTCAATATG; RV, GTGGGTTGCGGTTCTTT); (v) PITG_22087 (ATP-binding cassette superfamily) (FW, CCTTCTCCAGCG TTTCTTC; RV, CAGAAGAGCATTCCCATACC); and (vi) PITG_14461 (actin-like protein) (FW, CGGTCTATATGGGCCA GAAAT; RV, GGGTCCACCTTCAGCATTT). PITG_14461(actinlike protein) was used as a constitutively expressed endogenous control. RNA from isolates that had not been exposed to mefenoxam was used as the calibrator.

\section{RESULTS}

Acquired resistance. In agreement with previous studies, isolates belonging to lineage US-8 demonstrated preexisting resistance to mefenoxam (Fig. 2). Substantial growth was observed for lineage US- 8 growing on media containing 5 and $100 \mu \mathrm{g} \mathrm{ml}^{-1}$ mefenoxam. For example, at a concentration of $5 \mu \mathrm{g} \mathrm{ml}^{-1}$, US-8 did not differ significantly in growth from its mefenoxam-free control $(P \approx 1.00)$. Percent growth relative to the mefenoxam-free control for lineage US-8 was 94 and $65 \%$ at 5 and $100 \mu \mathrm{g} \mathrm{ml}^{-1}$, respectively.

All isolates from clonal lineages US-22, US-23, and US-24 were largely sensitive to mefenoxam. At concentrations of 5 and $100 \mu \mathrm{g} \mathrm{ml}{ }^{-1}$, these three lineages showed significantly reduced growth relative to mefenoxam-free controls as well as to US-8 $(P \leq 0.05)$. Isolates from these three clonal lineages that had no previous exposure to mefenoxam had radial growth of 16 to $29 \%$ of the diameter of control plates when grown on $100 \mu \mathrm{g} \mathrm{m}^{-1}$ mefenoxam (Fig. 2).

Prior exposure to mefenoxam had a significant effect on subsequent colony growth in the presence of mefenoxam. A significant three-way interaction between prior-exposure concentration of mefenoxam, lineage, and subsequent-exposure concentration of mefenoxam was observed $(P \leq 0.0001)$. All isolates of lineages US-22, US-23, and US-24 became resistant following exposure to mefenoxam at either 5 or $100 \mu \mathrm{g} \mathrm{ml}^{-1}(P \leq 0.05)$ (Fig. 2). For example, without prior exposure to mefenoxam, the isolate of US22 grew at $50 \%$ of the control on $5 \mu \mathrm{g} \mathrm{ml}^{-1}$ mefenoxam and $29 \%$ of the control on $100 \mu \mathrm{g} \mathrm{ml}^{-1}$ mefenoxam. With prior exposure to $5 \mu \mathrm{g} \mathrm{m}^{-1}$ mefenoxam, this isolate grew at $85 \%$ of the control on $5 \mu \mathrm{g} \mathrm{ml}^{-1}$ and $58 \%$ of the control on $100 \mu \mathrm{g} \mathrm{ml}^{-1}$ mefenoxam (Fig. 2 ). Without prior exposure to mefenoxam, the mean growth on $5 \mu \mathrm{g} \mathrm{ml}^{-1}$ mefenoxam for the two isolates of US-23 was $21 \%$ of the control on $5 \mu \mathrm{g} \mathrm{ml}^{-1}$ and $16 \%$ of the control on $100 \mu \mathrm{g} \mathrm{ml}^{-1}$ mefenoxam. With prior exposure to $5 \mu \mathrm{g} \mathrm{ml}^{-1}$ mefenoxam, their mean growth was $79 \%$ of the control on $5 \mu \mathrm{g} \mathrm{ml}^{-1}$ and $52 \%$ of the control on $100 \mu \mathrm{g} \mathrm{ml}^{-1}$ mefenoxam. Without prior exposure to mefenoxam, the mean growth on $5 \mu \mathrm{g} \mathrm{ml}^{-1}$ mefenoxam for the three isolates of US-24 was $42 \%$ of the control on $5 \mu \mathrm{g} \mathrm{m}^{-1}$ and $23 \%$ of the control on $100 \mu \mathrm{g} \mathrm{ml}^{-1}$ mefenoxam. With prior exposure to $5 \mu \mathrm{g} \mathrm{ml}^{-1}$ mefenoxam their mean growth was $79 \%$ of the control on $5 \mu \mathrm{g} \mathrm{ml}^{-1}$ and $77 \%$ of the control on $100 \mu \mathrm{g} \mathrm{m} \mathrm{m}^{-1}$ mefenoxam. For isolates belonging to sensitive lineages, increased resistance was also observed with prior exposure to $100 \mu \mathrm{g} \mathrm{ml}^{-1}$ mefenoxam (Fig. 2). Levels of resistance did not increase following a second exposure to mefenoxam (data not shown).

Maintenance of acquired resistance. The number of transfers through mefenoxam-free media had a significant effect on the maintenance of acquired resistance. Isolates that had been transferred a single time to mefenoxam-free medium tended to grow more slowly in the presence of mefenoxam compared to isolates that had been maintained on mefenoxam-amended medium $(P=$ 0.11 for an isolate on $5 \mu \mathrm{g} \mathrm{ml}^{-1}$ mefenoxam and $P=0.07$ for an
A
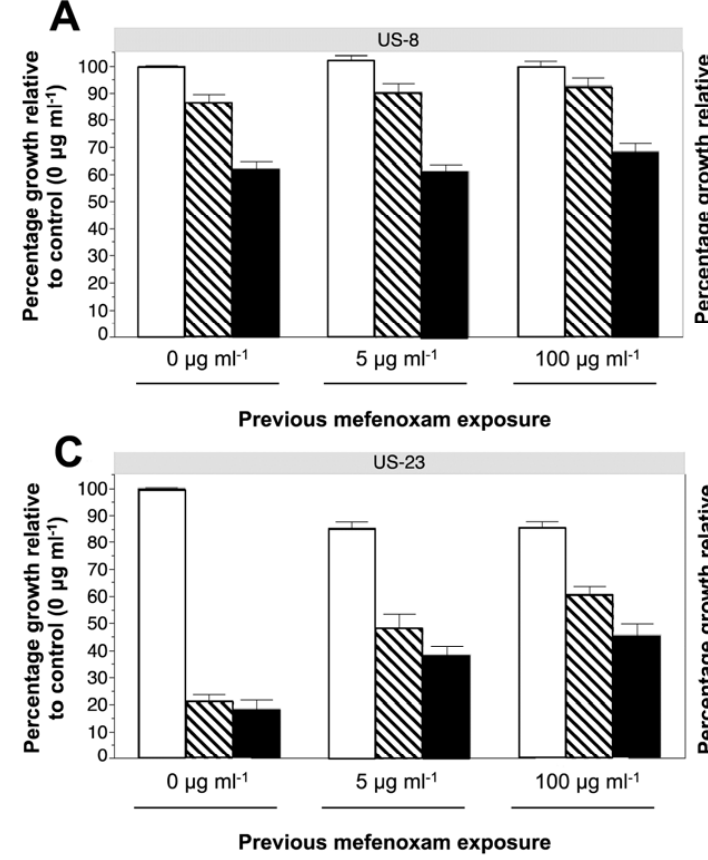

B

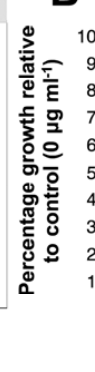

(1)
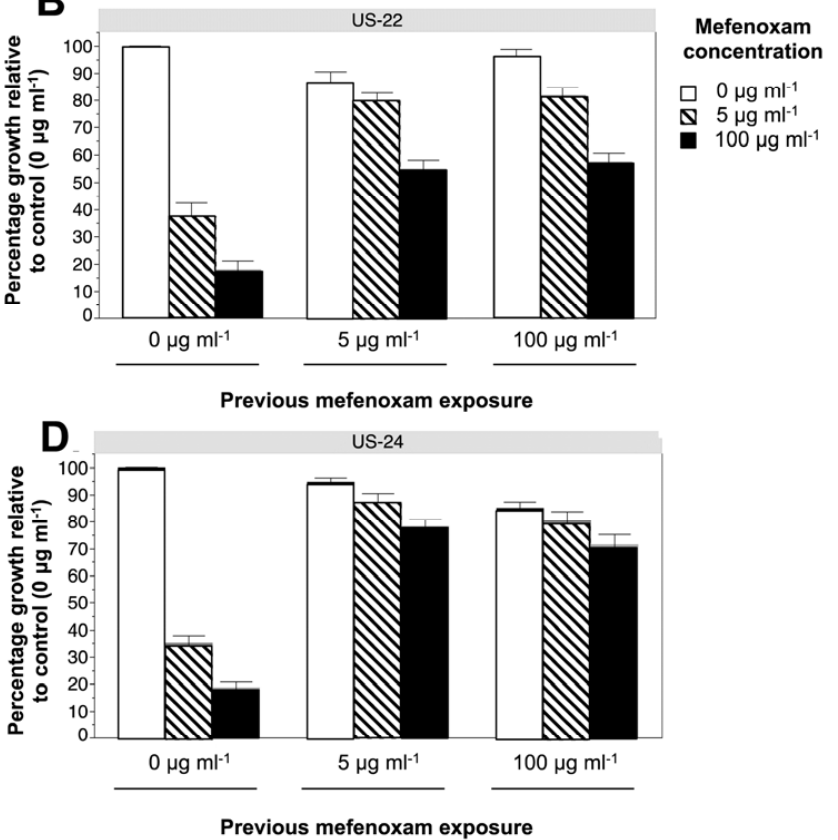

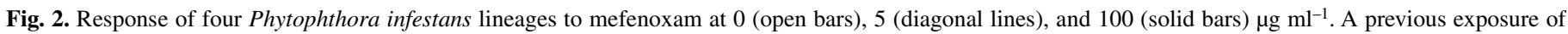

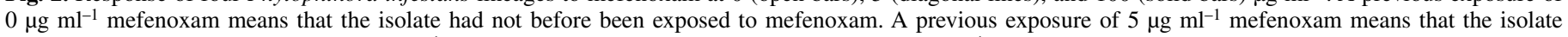

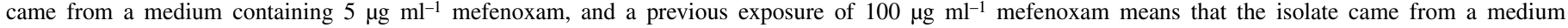

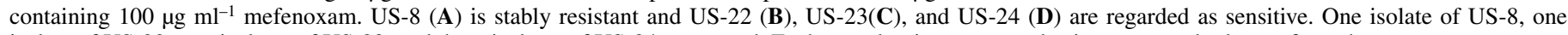
isolate of US-22, two isolates of US-23, and three isolates of US-24 were used. Each error bar is constructed using one standard error from the mean. 
isolate on $100 \mu \mathrm{g} \mathrm{ml}^{-1}$ mefenoxam). However, after two successive transfers on mefenoxam-free medium, the previously resistant isolates began to lose their acquired resistance and grew significantly more slowly on mefenoxam-containing medium (5 or $100 \mu \mathrm{g}$ $\left.\mathrm{ml}^{-1}\right)$ than those consistently maintained on mefenoxam $(P \leq 0.05)$.

Slower growth due to acquired resistance. Radial growth of isolates with acquired resistance was less on mefenoxam-free medium than was the radial growth of their originally sensitive parental individuals $(P \leq 0.0001)$. Mean relative growth rates for isolates that had been exposed previously to 5 or $100 \mu \mathrm{g} \mathrm{ml}^{-1}$ mefenoxam were 91 and $88 \%$, respectively. No significant twoway interaction between previous mefenoxam exposure $(0,5$, and $\left.100 \mu \mathrm{g} \mathrm{ml}^{-1}\right)$ and the number of transfers through mefenoxam-free media $\left(0 \mu \mathrm{g} \mathrm{ml}^{-1}\right)$ was observed $(P=0.41)$. After a single transfer to mefenoxam-free medium, isolates with prior exposure to mefenoxam (both 5 and $100 \mu \mathrm{g} \mathrm{ml}^{-1}$ ) showed significantly reduced growth in comparison with isolates that had never been exposed to mefenoxam $\left(0 \mu \mathrm{g} \mathrm{ml}^{-1}\right)(P \leq 0.0001)$. This reduced growth was maintained over three subsequent transfers on mefenoxam-free media. Reduced growth rate due to acquired resistance did not differ significantly between previous exposure to 5 or to $100 \mu \mathrm{g} \mathrm{ml}^{-1}$ mefenoxam $(P=0.27)$.

Whole-transcriptome sequencing. We obtained 177 million reads from sequencing the 24 distinct samples (four isolates, two treatments, three replications). After removal of reads aligning to rRNA, the number of reads per sample ranged from 5.5 to 9.5 million, of which 74 to $81 \%$ were aligned with the T30-4 draft genome to yield between 4.6 and 7.8 million raw counts per sample. Each library contained 14,273 to 15,492 expressed genes. When analyzed individually, isolates were found to have 535 to 1,152 genes differentially expressed with an FDR of less than 0.05 in response to mefenoxam.

Analysis of the raw counts using the edgeR package revealed that differential expression clustered largely by clonal lineage when analyzed via multidimensional scaling (figure not shown). Limited separation by treatment was found within these clusters, particularly within clonal lineage US-24.

Because of the phenotypic consistency of "acquired resistance" across all sensitive genotypes, we searched for genes that were differentially expressed in all sensitive genotypes in response to exposure to mefenoxam. This search revealed 32 candidate genes that were significantly differentially expressed in all three sensitive isolates with an FDR of less than 0.05 (Table 1). Of these 32 genes, nine were significantly down-regulated and 23 were significantly up-regulated. These genes included a phospholipase "Pi-PLD-like-3," two ATP-binding cassette superfamily (ABC) transporters, one mannitol dehydrogenase, three crinkling and necrosis (CRN) and five secreted RXLR effectors, and 17 conserved hypothetical proteins (Table 1), among others.
The genes that were differentially expressed in response to mefenoxam were also investigated in the stably resistant US-8 isolate. Among these 32 genes were 21 differentially expressed in common with the three sensitive isolates (Table 1).

Seventeen conserved hypothetical proteins were represented among the 32 genes that were commonly differentially regulated upon exposure to mefenoxam. The similarities of some of these proteins to those of known or hypothesized function are indicated in Table 2. These similarities are based on amino acid sequence similarity to other proteins determined by protein-protein BLAST analysis. Among these conserved hypothetical proteins, one was similar to a TonB membrane receptor from $P$. sojae and one was similar to both Avr1b-1 from P. sojae and a glycosylphosphatidyl inositol-anchored protein from $P$. infestans (Table 2).

Validation of RNA-seq results using qRT-PCR. To validate the RNA-seq results, we analyzed the expression profile of five genes that were differentially expressed between isolates unexposed and exposed to mefenoxam using qRT-PCR (Supplementary Figure 1). All of the five genes showed the same significant differential expression profiles with both techniques.

\section{DISCUSSION}

All individuals from all of the "sensitive" clonal lineages investigated became tolerant of mefenoxam upon exposure to mefenoxam after a single passage through mefenoxam-containing medium. Previous descriptions of such acquired resistance were detected after at least four to 12 passages through mefenoxamcontaining medium $(3,26)$. We found that repeated exposure had little impact on increasing this resistance. We suspect that the ability to acquire resistance may be a general characteristic of mefenoxam-sensitive isolates of $P$. infestans. Acquired resistance declined after two or three subcultures on medium free of mefenoxam, but we did not investigate whether the original level of mefenoxam sensitivity could be reached with additional transfers. In previous studies, diverse isolates of Phytophthora capsici and $P$. infestans responded diversely after many subcultures on mefenoxam-free medium, with some isolates losing resistance and others retaining it $(3,26)$.

We have demonstrated that sensitive lineages acquire resistance to mefenoxam if exposed to a nonlethal dose of mefenoxam. We suspect that acquisition of resistance is likely to be somewhat specific, but we have not systematically investigated other chemical or physical stresses to see if they also stimulate resistance to mefenoxam.

We also found that many sensitive isolates that had acquired resistance to mefenoxam seemed to be slightly retarded in growth in comparison to the parental isolates that had never been exposed to mefenoxam. Thus, it appeared that there is likely a cost associ-

TABLE 2. Possible functions of differentially expressed genes annotated as "conserved hypothetical proteins"

\begin{tabular}{|c|c|c|c|c|c|c|c|}
\hline $\begin{array}{l}\text { Broad gene } \\
\text { identifier }\end{array}$ & Annotation & $\begin{array}{l}\text { NCBI reference or } \\
\text { conserved domain }\end{array}$ & Organism & Annotation or domain & $\begin{array}{l}\text { Query } \\
\text { cover }\end{array}$ & Identity & E-value \\
\hline PITG_05795 & Conserved hypothetical protein & EGZ12418.1 & P. sojae & TonB receptor activity & $89 \%$ & $65 \%$ & $4.00 \mathrm{E}-70$ \\
\hline PITG_07573 & Conserved hypothetical protein & XP_002904561.1 & P. infestans & Predicted GPI-anchored protein & $59 \%$ & $98 \%$ & 0 \\
\hline PITG_02748 & Conserved hypothetical protein & $\begin{array}{l}\text { RING[cd00162], } \\
\text { PX[smart00312] }\end{array}$ & N/A & $\begin{array}{l}\text { RING Zn finger, PhoX homologous } \\
\text { domains }\end{array}$ & N/A & N/A & N/A \\
\hline PITG_10079 & Conserved hypothetical protein & RpsE[COG0098] & N/A & RpsERibosomal protein S5 domain & N/A & N/A & N/A \\
\hline PITG_10995 & Conserved hypothetical protein & $\begin{array}{l}\text { FYVE[cd00065], } \\
\text { DEP[cd04371], } \\
\text { PTZ00303 }\end{array}$ & $\mathrm{N} / \mathrm{A}$ & $\begin{array}{l}\text { FYVE Zn-binding, DEP, PTZ00303 } \\
\text { Phosphatidyl inositol kinase } \\
\text { (provisional) domains }\end{array}$ & N/A & N/A & N/A \\
\hline PITG_15627 & Conserved hypothetical protein & PRK12704 & $\mathrm{N} / \mathrm{A}$ & $\begin{array}{l}\text { PRK12704 Phosphodiesterase } \\
\text { (provisional) domain }\end{array}$ & N/A & N/A & N/A \\
\hline PITG_16013 & Conserved hypothetical protein & ATS1[COG5184] & N/A & $\begin{array}{l}\text { ATS1 Alpha-tubulin suppressor and } \\
\text { related RCC1 domain containing } \\
\text { multi-domain }\end{array}$ & N/A & N/A & N/A \\
\hline
\end{tabular}

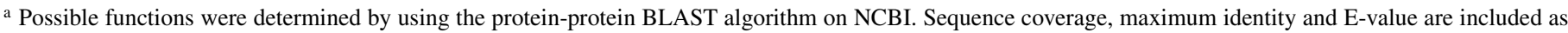
proxies for the level of similarity at the amino acid sequence level, between the annotated gene and the conserved hypothetical Phytophthora infestans gene. 
ated with acquired resistance, which possibly could affect fitness. Again, this observation is consistent with previous reports (3).

Isolates of US-8 had similar patterns of growth in response to mefenoxam, even after previous exposure. This does not preclude the possibility that acquired resistance is conserved in $P$. infestans, as it may be that the ability to acquire resistance in US-8 isolates is retained but masked or made unnecessary by the mechanism governing stable resistance to mefenoxam. The latter possibility is supported by the fact that US- 8 also differentially expresses many of the genes that are differentially expressed in common among the sensitive isolates. The genetic basis for inherited field resistance to mefenoxam is still unclear. It is known that mefenoxam has a negative effect on the synthesis of RNA and specifically on rRNA. Therefore, it likely involves the RNA polymerase I (RNApol1) as it transcribes rRNA. Randall et al. (22) identified and sequenced genes encoding RNApol1 subunits. They found that a small number of single-nucleotide polymorphisms (SNPs) in the gene encoding the large subunit of RNApol1 was specific to insensitive isolates. Yet, Howard Judelson's group has sequenced this same region for a number of $P$. infestans isolates from the United States and found that these SNPs did not account for all cases of resistance (personal communication). Judelson's group (personal communication) has observed the SNP identified by Randall et al. (22) to be associated with resistant genotypes in isolates of US-8, yet this same SNP was sometimes found in the sensitive isolates. Therefore, it is likely that another gene or group of genes contribute(s) to stable mefenoxam resistance in some genotypes of $P$. infestans.

Given the speed and consistency of acquired resistance, an epigenetic mechanism seemed likely. A wide range of mechanisms has been observed to confer fungicide or drug resistance in other systems, including efflux transport or direct detoxification of the active compounds (16). Thus, we compared the transcriptome of isolates without acquired resistance with the transcriptome of isolates with acquired resistance using RNA-seq.

The tight clustering by clonal lineage observed in the multidimensional scaling analysis showed that most genes differentially expressed between nonexposed (sensitive) and exposed (with acquired resistance) were unique to each isolate. Therefore, most differences were due to isolate rather than due to exposure to mefenoxam. However, common to all sensitive isolates that had acquired resistance were 32 genes that were differentially expressed in each of these lineages (Table 1).

We further investigated some of the genes that were most highly differentially expressed upon acquisition of resistance. They include genes with putative functions that could potentially mediate acquired resistance to mefenoxam. Notable among these are two $\mathrm{ABC}$ proteins, which are part of a large family of transporters characterized by a highly conserved nucleotide-binding domain (15). Most catalyze the ATP-dependent efflux of a broad spectrum of compounds from the cell (15). These have been observed to mediate drug and multidrug resistance in various organisms, including phytopathogenic fungi (20).

Another of the potential candidate genes is phospholipase D (PLD). These enzymes cleave phosphatidyl inositol into inositol and phosphatidic acid. A previous study with $P$. infestans has identified 18 such genes, many more than in other Eukaryotes (19). The same study also found that a few of those PLDs had extracellular activity and posited that they might play a role in modifying host tissues during pathogenesis. Phosphatidic acid has been implicated as a signal in diverse contexts including secretion, vesicle trafficking, and modulation of receptor signaling (31), which might aid removal of mefenoxam from the cell or interfere with the activity of mefenoxam. Additionally, PLDs have been directly implicated in agonist-dependent cellular secretion. Thus, this PLD might function as one of the steps in a signaling pathway leading to the acquired resistance response, perhaps via secretion of the molecule.
The conserved hypothetical protein showing similarity to a TonB-dependent receptor may play a role in mediating acquired resistance. This conserved hypothetical protein is similar in amino acid sequence to a TonB-dependent receptor protein found in $P$. sojae (29). TonB proteins are highly conserved and are anchored in the plasma membrane, projecting into the periplasmic space, where they often interact with receptors that are termed TonBdependent receptors (33). These receptors, often gated channels, are primarily known for their role in mediating iron uptake through the use of siderophores. However, TonB and the receptors it interacts with have been implicated in efflux-mediated "intrinsic and acquired antibiotic resistance" in Pseudomonas aeruginosa (33). This mechanism has been shown to influence but not entirely determine resistance (33). It is possible that these two conserved hypothetical proteins might work in concert with $\mathrm{ABC}$ transporters to mediate the efflux of mefenoxam.

The remaining candidate genes do not have previously documented roles in toxicant resistance but may be part of a stress response on the part of the pathogen - the stress being mefenoxam. Previous analyses of mannitol dehydrogenase in vitro show that it could be responsible for production of mannitol in the rust fungus, Uromyces fabae (30). Polyols like mannitol have been shown to function as an osmoprotectant in various fungi (4, $24,25)$. Thus, one hypothesis is that mannitol dehydrogenase is produced by $P$. infestans as a response to toxicants, either in general or as a specific osmoprotectant response.

RXLR effectors, on the other hand, are known primarily for their role in promoting virulence on host plants. The RXLR translocation motif is required for translocation across the host cell membrane, where RXLR effectors are presumed to participate in suppressing pathogen-associated-molecular-patterntriggered immunity $(2,32)$. The production of such specialized molecules in an in vitro test was unexpected, and a satisfying explanation for their induction awaits further investigation.

The identification of differentially regulated genes that are significantly expressed in common among the three originally sensitive isolates follows the assumption that these genotypes share a common mechanism for acquiring resistance. This assumption seems likely due to the similarity of the acquired resistance phenotypes among sensitive isolates. Also consistent with this hypothesis is the finding that the stably resistant US-8 isolate also differentially expressed many of the same genes that the sensitive isolates differentially express in common. However, because there was substantial diversity among isolates in the genes that were differentially expressed, we cannot rule out the possibility that different genotypes of $P$. infestans have different mechanisms responsible for their acquired resistance. Further work will be necessary to identify the precise mechanism(s) underlying acquired resistance. As a next step, a gene-specific silencing method should be used to test the role of the candidate genes identified in this study.

The risk of this acquired resistance causing problems in field situations seems low. Previous studies $(3,26)$ found that isolates that had acquired resistance in vitro did not have high levels of resistance in vivo. In our studies, isolates with acquired resistance had slower growth in culture and so might not compete well in the field. These results are consistent with those of Bruin and Edgington (3). However, it is also possible that acquired resistance might operate in concert with the stable resistance as described by Randall et al. (2014) to achieve an even greater level of resistance. It is also important for investigators to be aware that "sensitive" strains of $P$. infestans can rapidly acquire a resistance phenotype upon a single passage through mefenoxam-containing medium.

\section{ACKNOWLEDGMENTS}

This work was supported by Cornell University and by the Agriculture and Food Research Initiative Competitive Grants Program Grant 2011- 
68004-30154 from the U.S. Department of Agriculture. We thank D. Camuzeaux for technical assistance.

\section{LITERATURE CITED}

1. Benjamini, Y., and Hochberg, Y. 1995. Controlling the false discovery rate: A practical and powerful approach to multiple testing. J. R. Stat. Soc. Ser. B (Methodol.) 57:289-300.

2. Birch, P. R., Armstrong, M., Bos, J., Boevink, P., Gilroy, E. M., Taylor, R. M., Wawra, S., Pritchard, L., Conti, L., Ewan, R., Whisson, S. C., van West, P., Sadanandom, A., and Kamoun, S. 2009. Towards understanding the virulence functions of RXLR effectors of the oomycete plant pathogen Phytophthora infestans. J. Exp. Bot. 60:1133-1140.

3. Bruin, G. C. A., and Edgington, L. V. 1981. Adaptive resistance in Peronosporales to metalaxyl. Can. J. Plant Pathol. 3:201-206.

4. Clark, A. J., Blissett, K. J., and Oliver, R. P. 2003. Investigating the role of polyols in Cladosporium fulvum during growth under hyper-osmotic stress and in planta. Planta 216:614-619.

5. Cohen, Y., and Coffey, M. D. 1986. Systemic fungicides and the control of oomycetes. Annu. Rev. Phytopathol. 24:311-338.

6. Danies, G., Small, I. M., Myers, K., Childers, R., and Fry, W. E. 2013. Phenotypic characterization of recent clonal lineages of Phytophthora infestans in the United States. Plant Dis. 97:873-881.

7. Davidse, L. C., Danial, D. L., and Van Westen, C. J. 1983. Resistance to metalaxyl in Phytophthora infestans in the Netherlands. Neth. J. Plant Pathol. 89:1-20.

8. Dowley, L. J., and O'Sullivan, E. 1981. Metalaxyl-resistant strains of Phytophthora infestans (Mont.) de Bary in Ireland. Potato Res. 24:417421.

9. Dowley, L. J., and O'Sullivan, E. 1985. Monitoring metalaxyl-resistant strains of Phytophthora infestans (Mont.) de Bary in Ireland. Potato Res. 28:531-534.

10. Fry, W. E., McGrath, M. T., Seaman, A., Zitter, T. A., McLeod, A., Danies, G., Small, I. M., Myers, K., Everts, K., Gevens, A. J., Gugino, B. K., Johnson, S. B., Judelson, H., Ristaino, J., Roberts, P., Secor, G., Seebold, K., Snover-Clift, K., Wyenandt, A., Grünwald, N. J., and Smart, C. D. 2013. The 2009 late blight pandemic in the eastern United StatesCauses and results. Plant Dis. 97:296-306.

11. Goodwin, S. B., Sujkowski, L. S., and Fry, W. E. 1996. Widespread distribution and probable origin of resistance to metalaxyl in clonal genotypes of Phytophthora infestans in the United States and western Canada. Phytopathology 86:793-800.

12. Grünwald, N. J., and Flier, W. G. 2005. The biology of Phytophthora infestans at its center of origin. Annu. Rev. Phytopathol. 43:171-190.

13. Hu, C. H., Perez, F., Donohoo, R., McLeod, A., Myers, K., Ivors, K., Secor, G., Roberts, P., Deahl, K. L., Fry, W. E., and Ristaino, J. B. 2012. Recent genotypes of Phytophthora infestans in eastern USA reveal clonal populations and reappearance of mefenoxam sensitivity. Plant Dis. 96:1323-1330.

14. Judelson, H. S., and Roberts, S. 1999. Multiple loci determining insensitivity to phenylamide fungicides in Phytophthora infestans. Phytopathology 89:754-760.

15. Judelson, H. S., and Senthil, G. 2006. Investigating the role of ABC transporters in multifungicide insensitivity in Phytophthora infestans. Mol. Plant Pathol. 7:17-29.

16. Langmead, B., Trapnell, C., Pop, M., and Salzberg, S. L. 2009. Ultrafast and memory-efficient alignment of short DNA sequences to the human genome. Genome Biol. 10:R25.

17. Lee, T. Y., Mizubuti, E., and Fry, W. E. 1999. Genetics of metalaxyl resistance in Phytophthora infestans. Fungal Genet. Biol. 26:118-130.

18. Matuszak, J. M., Fernandez-Elquezabal, J., Gu, W.-K., VillarrealGonzalez, M., and Fry, W. E. 1994. Sensitivity of Phytophthora infestans populations to metalaxyl in Mexico: Distribution and dynamics. Plant Dis. 78:911-916.
19. Meijer, H. J. G., Hassen, H. H., and Govers, F. 2011. Phytophthora infestans has a plethora of Phospholipase D enzymes including a subclass that has extracellular activity. PloS ONE 6(3):e17767. doi:10.1371/ journal.pone. 0017767

20. Nakaune, R., Hamamoto, H., Imada, J., Akutsu, K., and Hibi, T. 2002. A novel ABC transporter gene, PMR5, is involved in multidrug resistance in the phytopathogenic fungus Penicillium digitatum. Mol. Genet. Genomics 267:179-185.

21. Pfaffl, M. W., Horgan, G. W., and Dempfle, L. 2002. Relative expression software tool (REST) for group-wise comparison and statistical analysis of relative expression results in real-time PCR. Nucleic Acids Res. 30:e36.

22. Randall, E., Young, V., Sierotzki, H., Scalliet, G., Birch, P., Cooke, D., Csukai, M., and Whisson, S. 2014. Sequence diversity in the large subunit of RNA polymerase I contributes to Mefenoxam insensitivity in Phytophthora infestans. Mol. Plant Pathol. 15: 664-676.

23. Robinson, M. D., McCarthy, D. J., and Smyth, G. K. 2010. edgeR: A bioconductor package for differential expression analysis of digital gene expression data. Bioinformatics 26:139-140.

24. Shen, B., Jensen, R. G., and Bohnert, H. J. 1997. Increased resistance to oxidative stress in transgenic plants by targeting mannitol biosynthesis to chloroplasts. Plant Physiol. 113:1177-1183.

25. Shen, B., Jensen, R. G., and Bohnert, H. J. 1997. Mannitol protects against oxidation by hydroxyl radicals. Plant Physiol. 115:527-532.

26. Staub, T., Dahmen, H., Urech, P., and Schwinn, F. 1979. Failure to select for in vivo resistance in Phytophthora infestans against acylalanine fungicides. Plant Dis. Rep. 63:385-389.

27. Therrien, C. D., Tooley, P. W., Spielman, L. J., Fry, W. E., Ritch, D. L., and Shelly, S. E. 1993. Nuclear-DNA content, allozyme phenotypes and metalaxyl sensitivity of Phytophthora infestans from Japan. Mycol. Res. 97:945-950.

28. Trapnell, C., Pachter, L., and Salzberg, S. L. 2009. TopHat: Discovering splice junctions with RNA-Seq. Bioinformatics 25:1105-1111.

29. Tyler, B. M., Tripathy, S., Zhang, X., Dehal, P., Jiang, R. H., Aerts, A., Arredondo, F. D., Baxter, L., Bensasson, D., Beynon, J. L., Chapman, J., Damasceno, C. M., Dorrance, A. E., Dou, D., Dickerman, A. W., Dubchak, I. L., Garbelotto, M., Gijzen, M., Gordon, S. G., Govers, F., Grunwald, N. J., Huang, W., Ivors, K. L., Jones, R. W., Kamoun, S., Krampis, K., Lamour, K. H., Lee, M. K., McDonald, W. H., Medina, M., Meijer, H. J., Nordberg, E. K., Maclean, D. J., Ospina-Giraldo, M. D., Morris, P. F., Phuntumart, V., Putnam, N. H., Rash, S., Rose, J. K., Sakihama, Y., Salamov, A. A., Savidor, A., Scheuring, C. F., Smith, B. M., Sobral, B. W., Terry, A., Torto-Alalibo, T. A., Win, J., Xu, Z., Zhang, H., Grigoriev, I. V., Rokhsar, D. S., and Boore, J. L. 2006. Phytophthora genome sequences uncover evolutionary origins and mechanisms of pathogenesis. Science 313:1261-1266.

30. Voegele, R. T., Hahn, M., Lohaus, G., Link, T., Heiser, I., and Mendgen, K. 2005. Possible roles for mannitol and mannitol dehydrogenase in the biotrophic plant pathogen Uromyces fabae. Plant Physiol. 137:190-198.

31. Wang, X., Devaiah, S. P., Zhang, W., and Welti, R. 2006. Signaling functions of phosphatidic acid. Prog. Lipid Res. 45:250-278.

32. Whisson, S. C., Boevink, P. C., Moleleki, L., Avrova, A. O., Morales, J. G., Gilroy, E. M., Armstrong, M. R., Grouffaud, S., van West, P., Chapman, S., Hein, I., Toth, I. K., Pritchard, L., and Birch, P. R. 2007. A translocation signal for delivery of oomycete effector proteins into host plant cells. Nature 450:115-118.

33. Zhao, Q., Li, X. Z., Mistry, A., Srikumar, R., Zhang, L., Lomovskaya, O., and Poole, K. 1998. Influence of the TonB energy-coupling protein on efflux-mediated multidrug resistance in Pseudomonas aeruginosa. Antimicrob. Agents Chemother. 42:2225-2231.

34. Zhong, S., Joung, J., Zheng, Y. L., Chen, Y., Liu, B., Shao, Y., Xiang, J. Z., Fei, Z., and Giovannoni, J. 2011. High-throughput Illumina strandspecific RNA sequencing library preparation. Cold Spring Harbor Laboratory, Cold Spring Harbor, NY. 